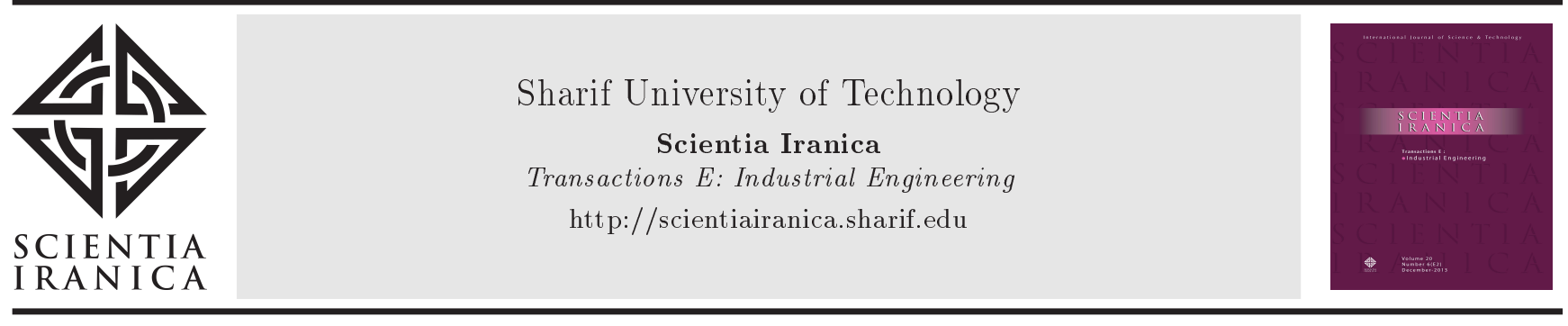

\title{
A tabu search algorithm for a multi-period bank branch location problem: A case study in a Turkish bank
}

\author{
A. Basar, Ö. Kabak*, and Y.I. Topcu \\ Department of Industrial Engineering, Istanbul Technical University, Macka Campus 34357, Istanbul, Turkey. \\ Received 5 April 2017; received in revised form 20 January 2018; accepted 14 May 2018
}

\author{
KEYWORDS \\ Integer programming; \\ Decision support \\ system; \\ Tabu Search (TS); \\ Case study; \\ Banking; \\ Location.
}

\begin{abstract}
Banks need to open new branches in new sites as a result of an increase in the population, promotion of individual earnings, and growth in national economy. In this respect, opening new branches or reorganizing the locations of current branches is an important decision problem for banks to accomplish their strategic objectives. This paper presents a decision support method for multi-period bank branch location problems. The aim is to find bank branch locations based on transaction volume, distance between branches, and cost of opening and closing branches. The proposed method not only develops an integer program and a Tabu Search (TS) algorithm to find the exact places of branches, but also presents a structuring method to identify the related criteria and their importance. We demonstrate the effectiveness of the method on random data. In the final stage, the method is applied to a Turkish bank's branch location problem considering the current and possible places of the branches, availability of the data, and the bank's strategies for a four-year strategic planning.
\end{abstract}

(C) 2019 Sharif University of Technology. All rights reserved.

\section{Introduction}

Banks contribute to economic development and the improvement of living standards by using their funds borrowed from individuals, businesses, financial institutions, and governments to make loans or purchase securities. They provide their customers with different products such as mortgages, credits, bank accounts, and portfolio management to earn profit. They spend their profit in the local economy as well as in regional or national businesses. Thus, they have fundamental roles both in local and global economy $[1,2]$.

Opening new branches or reorganizing the lo-

\footnotetext{
*. Corresponding author. Tel.: +90 2122931300 (2039);

Fax: +90212240 72 60

E-mail addresses: ayferbasar@gmail.com (A. Basar);

kabak@itu.edu.tr(Ö.Kabak); topcuil@itu.edu.tr (Y.I.

Topcu)
}

doi: $10.24200 /$ sci.2018.20493 cations of current branches is an important decision problem for banks to accomplish their strategic objectives. Although the alternative distribution channels have been widely used, banks increase the number of potential customers and improve their loyalty at branches. Naturally, banks sometimes need to open new branches to deal with the effects of an increase in population, promotion of individual earnings, and growth in the national economy. The Turkish Banking Association reported that the number of bank branches in Turkey increased by $5.35 \%$ in 2013 [3]. In respect of Retail Banker International reports, JPMorgan and Chase opened about 90 branches in one-month period and, thereby, raised the number of branches to approximately 5,700 [4]. These examples show the importance of the branch location problem for banks.

Formally, the bank branch location problem can be defined as follows [5]. Suppose that a bank plans to open some new and close existing branches where candidate locations for opening new branches and sites 
of available branches are already known. The aim of the problem is to find an optimal configuration of the branches by deciding which branches to close and where to open new ones. A set of criteria which are specified depending on the bank's strategies should be employed to make this decision. The classical objectives of this decision are (1) to maximize the profit of the branches depending on the criteria determined and (2) to minimize the cost function (e.g., the number of branches and the total weighted travel distance for customers).

This problem can be extended through the introduction of different branch types since banks may have specific branch types to provide special services to specific customer segments such as individual, commercial, private, corporate, entrepreneur, and Small- and Medium-sized Enterprise (SME) banking. On the other hand, the problem can be modeled on a time horizon with a multi-period nature, since the location decision of bank branches has long-term effects; most of the parameters (i.e., demand, costs, etc.) can change after a while, and opening/closing branches may come to order in different periods. There are numerous studies on multi-period location models, also referred to as dynamic location models, in the literature. On the other hand, most of the dynamic models focus on only the changing parameters. In some dynamic models, the location decision is considered at an operational level by changing the decision according to short-term conditions such as daily or hourly (i.e., ambulance redeployment or relocation) [6]. Our study is different in terms of determining the locations of bank branches over a long-term planning horizon. We have re-formulated the mathematical model in [5] for the multiple-period case. Additionally, we have also revised the Tabu Search (TS) algorithm in [5] for the multiperiod environment. We have made a comparison of the results of the current study with those of the singleperiod cases in detail. We have found that the multiperiod problem could be considered as more reliable for the given strategic decisions for multiple periods.

Although location problems for emergency service stations, fire stations, etc. are broadly discussed in the literature, the bank branch location problem is much less considered. Among the few studies, most use Multi-Criteria Decision Making (MCDM) approaches. They evaluate possible sites with respect to the criteria and use the final rankings to locate new branches. On the other hand, the current mathematical models try to solve a pre-defined problem for a single period. According to our extensive literature review, which is presented in the following section, the main gap in the literature is related to a structured method for specifying the decision criteria and a method that considers the multi-criteria and multi-period nature of this strategic problem. To the best of our knowledge, there is no multi-period location model developed for and applied to the bank branch location problem in the literature.

In order to fill this gap, this paper presents a decision support method for multi-period bank branch location problems with multiple branch types. Basically, in the multi-period problem, locations of bank branches are determined over a planning horizon of a number of periods with a given maximum number of branches that can be opened in each period. It is required that the branches used to be open in a period remain open for certain periods in the time horizon. In this context, the model can be considered as a strategic problem for the banks. In the current study, first, a set of criteria is selected according to a comprehensive literature review and experts' opinions. According to this review and the experts' opinions, transaction volume of candidate branches was discovered to have high importance and effect on branches' profitability [713]. In addition to transaction volume, experts also placed value in penalty of opening branches close to each other and cost of opening and closing a branch as the other main criteria. Next, weights of the criteria are specified for different types of branches based on experts' judgment delivered by pairwise comparisons. Furthermore, a multi-period mathematical program that aims to maximize the total net profit of the different types of bank branches is proposed. Since an optimal solution cannot be obtained even for smallsized problems, TS algorithm is developed. The results of the TS are compared with those of the proposed mathematical program. Finally, the proposed method is applied to a Turkish bank to locate its branches in Istanbul, and the robustness of the method is tested through duality analysis.

The remaining parts of the paper are organized as follows. Section 2 is dedicated to the literature review about location planning in a multi-period manner and bank branch location problem. The details of the proposed methodology and experimental study for the TS are provided in Sections 3 and 4, respectively. The application of the proposed method in a Turkish bank is presented in Section 5. Finally, conclusions and future research are provided in Section 6 .

\section{Literature review}

Opening new facilities in appropriate places is one of the most important decision supporting strategies for any institution. Facility location models have, therefore, been extensively used in studies on location problems of fire, ambulance, police stations, etc. Basar et al. [14] developed a taxonomic study to investigate the location problems, which are deterministic or stochastic, including single- or multi-period location decision, etc. Arabani and Farahani [15] presented a 
review of different site selection problems from distinct aspects. Mainly, facility location problems can be categorized as single- or multi-period depending on the number of periods in the planning horizon, in which location decision is made. Multi-period location problems are handled in detail in subsequent sections; interested readers are referred to [5] for a comprehensive tutorial on single-period location problems.

\subsection{Multi-period location models}

Since the parameters affecting the location decisions, such as customer demand and transportation costs, change over time, all facilities cannot be opened at once because of budget constraints. In addition, location decision is a strategic, multi-period location problem (or "dynamic location problems" as used in some studies), which has come to gain importance for both researchers and practitioners. By considering a planning horizon, Miller et al. [16] considered that multi-period location problems provided the appropriate timing of location decision and clarification of the best locations. Therefore, firms can better anticipate fluctuations in customer demand in the corresponding time horizon as distinct from single-period models. They are also more efficient than single-period models are, since planners can easily deal with unstable parameters in each planning horizon [17-19].

Wesolowky and Truscott [20] proposed a multiperiod model to minimize total costs including the assignment of all facilities to their corresponding demand points and the removal and establishment of a facility. Schilling [21] proposed a multi-period model by considering the single coverage of demand nodes and associating the service in different periods with importance, representing the relative importance of that period. Gunawardane [22] extended the Maximal Covering Location Problem (MCLP) by considering a planning horizon to solve the problem in the multiperiod scenario. Galvao and Gonzalez [23] developed a Lagrangian heuristic to investigate the $p_{k}$-Median multi-period location problem to minimize the openingrelocating problem of the facilities and transportation costs. Drezner [24] studied multi-period $p$-Median problem. Next, Chardaire et al. [25] proposed $0-1$ quadratic programming model to study the multiperiod facility location and solved the model by simulated annealing and Lagrangian Relaxation. Hormozi and Khumawala [26] developed an exact algorithm to solve the multi-period location problem by integrating mixed integer with dynamic programing techniques. Current et al. [27] addressed the multi-period location of multiple facilities when the total number of facilities was uncertain during the planning horizon. They proposed two different objectives: the minimization of expected opportunity loss and of maximum regret. Antunes and Peeters [28] presented a multi-period model for school network planning by allowing the opening and closing of facilities and both the reducing and expanding of their capacity. The previous study of Antunes and Peeters [29] was extended by applying simulated annealing for their proposed mixed-integer linear optimization models. Canel et al. [30] proposed an algorithm for the capacitated, multi-commodity multi-period facility location problem. Dias et al. [31] proposed a multi-period location problem that allows facilities to open, close, and reopen more than once during the planning horizon and applied a primal-dual heuristic. Rajagopalan et al. [6] developed a multiperiod set covering location model for the redeployment of ambulances to determine the minimum number of ambulances and their locations for each time horizon with the coverage requirement of predetermined reliability. Albareda-Sambola et al. [32] introduced the multi-period incremental service facility location problem to minimize the sum of assignment and facility opening costs. They opened a predetermined number of facilities in each period to serve a limited number of customers assigned to these facilities. In their model, all customers must be assigned to a facility until the end of horizon. They used a Lagrangian heuristic to solve the problem. Basar et al. [33] proposed a multi-period backup double covering model to maximize the total population serviced by two distinct facilities within two different response time limits over a planning horizon and, then, used TS to solve the problem. TorresSoto and Uster [34] proposed Lagrangian relaxation and Bender's decomposition algorithms for the multiperiod capacitated facility location problems. Sha and Huang [35] studied a multi-period location-allocation problem about healthcare systems and, then, developed a case study in Beijing. They proposed a heuristic method based on Lagrangian relaxation. Ghaderi and Jabalameli [36] presented a multi-period uncapacitated facility location problem with a budget constraint. They solved the model by using two heuristics (greedy and fix-and-optimize) based on simulated annealing and compared the results with the CPLEX solver. Zarandi et al. [37] used simulated annealing to solve multi-period MCLP. Miskovic et al. [38] proposed a variable neighborhood search method for optimizing the emergency service network of police special force units in a multi-period manner to minimize the maximum load of established emergency units in all time periods. They solved real-life instances and compared the results with CPLEX. Only some related studies in the literature are mentioned; for instance, interested readers are referred to the referenced studies $[39,40]$ for a comprehensive tutorial about the multi-period location problem.

Although there are many multi-period location models discussed in the literature, none of them considered the decision criteria affecting the selection of 
optimum location. Moreover, as stated by Da Gama and Captivo [41], the multi-period location models discussed in the literature generally are focused on minimizing the total cost over the planning horizon by making sure that the demand in each period is satisfied, the reopening of an once-removed facility is avoided, or a facility that has been established earlier during the planning horizon is removed. They are generally focused on minimizing operation costs (e.g., opening and closing facilities, hiring and firing workers, and assigning customers to newly opened facilities) or distance over the time horizon. Additionally, literature does not cover multi-period location problems that specifically focus on bank branch location.

This study takes into account a set of criteria determined by a comprehensive literature search and experts' judgment and applies these criteria in a new mathematical model that has been suggested for a multi-period bank branch location problem. Therefore, the objective function of the proposed model includes three main factors such as the expected revenue, operating costs relating to opening and closing branches, and the cost relating to proximity of the same type of branch near each other. Here, an attempt is made to maximize the total profit of bank branches over the planning horizon, considering their revenue affected by different criteria and costs. The model can be applied both for deciding on the efficient sites for branches and for evaluating the performance of available branches over the time horizon. Moreover, since the model is developed to support strategic management decisions, we guarantee that some branches stay in service by a set of constraints. According to Current et al. [27], there are two types of multi-period location models:

(i) Explicit models in which facilities can be opened and closed during the planning horizon due to the unstable parameters;

(ii) Implicit models in which all the facilities are opened in the first period and stay open over the time horizon. The proposed model is a combination of explicit and implicit models, because while the branches can be opened and closed, some opened branches are restricted not to be closed for a time period during the planning horizon. Using the real-life application of the proposed method, this study determines the penalty of opening the same type of branch near each other and ease of access based on the transportation network of Istanbul using the GIS; thus, realistic solutions can be found.

\subsection{Bank branch location problem in the literature}

In general, statistical analysis, MCDM, and mathematical programming are the most common methods used in the literature to open bank branches in the best places.

Among the statistical models, linear regression is extensively used in the literature. Clawson [42] presented stepwise linear regression to identify performance criteria for candidate locations and specified a number of corrective actions for underperforming branches. In order to assess the performance of both current branches and potential sites for a Greek bank, Boufounou [43] used regression analysis and performed statistical tests. Ravallion and Wodon [44] recommended using regression analysis for the clarification of the association between different factors and Bangladesh's Grameen Bank branch locations. Basar et al. [45] used regression analysis to determine the importance and effect of different criteria such as population, social and trade potential, competition, and financial income on the transaction volume in order to find the best locations for bank branches. Aggelopoulos and Georgopoulos [46] found the factor of deposit-oriented activity, such as current and saving accounts, to be a significant driver. They considered an increase in the deposit balances as an important key performance indicator in the Greek banking system. In this regard, Cvetkoska and Savić [47] and Quaranta et al. [48] proposed two- and three-phase approaches to measure bank branch efficiency, consecutively.

MCDM techniques are commonly used for bank branch location problems [49]. Min [50] suggested using fuzzy goal programming for the commercial bank branch location problem in Ohio. Cinar [51] proposed fuzzy Analytical Hierarchy Process (AHP) and TOPSIS methods open a new branch in the best location among six cities in the South Eastern part of Turkey. Rahgan and Mirzazadeh [52] suggested using fuzzy AHP and evidential reasoning techniques to determine criteria importance and rank the location alternatives, respectively. Morrison and O'Brien [53] used Geographical Information Systems (GIS) and a spatial interaction model in four phases by forecasting the probability of customers coming over a branch, specifying customers' expected distribution, computing the anticipated number of transactions in a specified branch, and finding the effect of closing one or more branches. Basar et al. [5] used pairwise comparisons based on an expert's judgment to determine the importance of the proposed criteria for four different types of bank branches. Gorener et al. [54] proposed AHP method to prioritize criteria and multi-objective optimization on the basis of ratio analysis to rank alternative locations for bank branches.

As also stated by Basar et al. [49], although the literature about the mathematical programming relating to the facility location problems is vast, the studies relating to both single- and multi-period bank branch location problems are insufficient. Min 
and Melachrinoudis [55] considered risk and uncertainty, used constrained goal programming in a threelevel location-allocation model, and implemented their methodology in the USA. By means of GIS, Miliotis et al. [56] Miliotis et al. [56] maximized coverage to specify the minimum number of branches and applied their approach to a bank in Greece. Wang et al. [57] solved a bank branch location problem in New York by applying greedy interchange, TS, and Lagrangian relaxation. The problem is the extended version of the $p$-median problem with a budget constraint for opening and closing branches. Monteiro and Fontes [58] minimized the total cost for the bank-branch restructuring problem using a mixed linear model and proposed a local search heuristic by applying drop and swap operations. They focused on minimizing total costs (operating, opening and closing, hiring and firing employee, and penalty and service) without considering the potential revenue of each branch. Zhang and Rushton [59] maximized the total benefit by considering the constraints associated with opening branches and customer waiting time. They proposed a genetic algorithm to solve the problem. Alexandris and Giannikos [60] developed a model to maximize the total population covered by the chosen branches. Xia et al. [61] proposed a hybrid nested partitioning algorithm by taking into account demand, distance between branches, operations, and rental costs.

Finally, to the best of our knowledge, there is no multi-period location model developed for and applied to the problem related to locating bank branches. On this account, this study suggests a method to find the exact sites of bank branches in a multi-period plan using a mathematical program. Our method includes a problem structuring phase (i.e., identifying the criteria and finding their importance) to provide the necessary information for the mathematical program and the TS algorithm to solve it effectively.

\section{Proposed method}

The proposed method is intended to solve a multi- period bank branch location problem. First, the criteria related to the problem and their importance weights are found. Next, an integer program is improved to specify the locations of branches. Finally, since the proposed integer program cannot be solved optimally in a convenient time for the real-life sized problems, a TS approach is improved. The following subsections explain these steps in detail.

\subsection{Identifying the criteria and their importance}

Banks prefer opening special types of branches to reduce their operational costs and raise the effectiveness of their related processes. Based on experts' opinions and market research in banking, according to Basar et al. [5], individual, entrepreneur, corporate, and commercial types of branches are the most common types for almost all banks. Moreover, they identified the criteria through a detailed literature survey and experts' opinions [5]. While reviewing the literature, it is seen that many criteria (e.g., population, average per capita domestic income, home ownership rate, commercial potential, demographic characteristics, average household size, income level, etc.) are used in different studies, and there are no common criteria for the bank branch location problem. On the other hand, Data Envelopment Analysis (DEA) for bank branches was applied [11-13], implying that transaction volume is one of the most prevalent factors in most studies. In addition to the literature review, experts' opinions are also gathered to identify the criteria through a questionnaire by means of one-to-one interviews made with the banking sector experts. Finally, transaction volume is specified as an important criterion for bank branch profit in parallel with the other related literature $[9,10,62]$. Since using real data of transaction volume is almost impossible due to the confidentiality requirement of banks, transaction volume is forecasted by different criteria and sub-criteria depending on both the literature survey and experts' opinion. Finally, the selected criteria for estimating transaction volume are given in Table 1.

Table 1. Criteria used for the estimation of transaction volume.

\begin{tabular}{ll}
\hline \multicolumn{1}{c}{ Criteria } & \multicolumn{1}{c}{ Proposed sub criteria } \\
\hline Number of potential customers & Total population, number of private and financial institutions, \\
hospitals, and education places \\
Socioeconomic status & Education level, and number of summer houses \\
Social potential & Number of education and entertainment places, and hospitals \\
Commercial potential & Number of private institutions, shopping centers, car parks, financial institutions, \\
Ease of access & and car services \\
Competition & Distance to neighboring potential branches \\
Financial situation & Number of competitors' bank branches \\
\hline
\end{tabular}


Table 2. Importance of main criteria [5].

\begin{tabular}{lccccc}
\hline \multicolumn{1}{c}{ Criteria } & Notation & Individual & Entrepreneur & Corporate & Commercial \\
\hline Transaction volume & $c_{1 j}$ & 0.51 & 0.56 & 0.51 & 0.52 \\
Distance between branches & $c_{2 j}$ & 0.32 & 0.27 & 0.30 & 0.30 \\
Cost of opening a new branch & $c_{3 j}$ & 0.10 & 0.09 & 0.12 & 0.12 \\
Cost of closing a branch & $c_{4 j}$ & 0.07 & 0.08 & 0.07 & 0.06 \\
\hline
\end{tabular}

Criteria in Table 1 include some other factors relating to deposit-oriented activity. For instance, socioeconomic status and financial situation cover the rate of retirees representing the population willing to save money, etc. In addition to transaction volume, distance between the candidate locations is identified as the main factor for the bank branch location problems according to experts' judgment. Thus, opening new (same type) branches in close proximity is penalized so that opening multiple branches nearby is prevented. Moreover, opening and closing costs are considered as two other main criteria.

After specifying all the criteria and related sub criteria, the importance of each criterion is identified. It is not convenient to use an objective method for determining importance, such as regression analysis, due to the lack of real data resulting from banking privacy; therefore, an appropriate subjective method is required to obtain the importance of the specified criteria. Among different subjective techniques such as rating, point allocation, etc., the pairwise comparison provides more acceptable solutions since decisionmakers concentrate on finding the relative weight of only two criteria at each time [63]. Decision-makers are also not affected by external factors and are knowledgeable about the criteria that they evaluate. Moreover, the pairwise comparison is the main technique of AHP, originally proposed by Saaty [64], and it is one of the most frequent methods both in decision-making and location problems [65-68]. Furthermore, since the bank branch location problem can be modeled by a hierarchy including the decision goal and related criteria, a pairwise comparison is found to be an effective method for determining the importance of criteria.

Basar et al. proposed a pairwise comparison method [5]. In this particular study, 10 experts who are top managers in the Turkish banking sector evaluated the relative importance of four main criteria (transaction volume, distance between potential locations, and opening and closing costs), factors affecting transaction volume (number of potential customers, socioeconomic status, social potential, commercial potential, ease of access, competition, and financial situation), and all sub-criteria (e.g., total population, number of private institutions, financial institutions, hospitals and education places for number of potential customers, etc.) through one-on-one interviews for four different types of branches. After obtaining the assessment of each expert via pairwise comparisons, Basar et al. [5] identified the importance of all the main and sub-criteria. The resulting importance values of the main criteria are given in Table 2 .

As seen in Table 2, transaction volume is the most important main criterion for all branch types. Compared to the others, distance between branches also has high importance and effect on banks with no desire to open the same type of branches very close to each other.

\subsection{Proposed multi-period mathematical program}

According to related literature survey, while there are a few mathematical models developed for the single-period bank branch location problem, there is a shortcoming and requirement for models that deal with multi-period problems. In banking, the number of total branches in terms of different branch types to open is generally planned in multiple periods and is known in each period due to the bank's strategy as well as the budget constraints. Therefore, it is assumed here that the total number of new branches (or total number of branches) and the minimum number of each type of branch are known for each period in the planning horizon. Moreover, some branches cannot be closed as a result of particular bank's strategy (for instance, in our case study, branches opened in a certain period could not be closed within the following three periods). Thus, a new multi-period mathematical program to locate bank branches is defined as follows (see Table 3 for the notation):

$$
\begin{aligned}
\max & \sum_{t \in T} \sum_{i \in I} \sum_{j \in J} c_{1 j} h_{i j}^{t} x_{i j}^{t} \\
& -\sum_{t \in T} \sum_{i \in I} \sum_{m \in I, i \neq m} \sum_{j \in J} c_{2 j} \lambda_{i m j}^{t} \\
& -\sum_{t \in T} \sum_{i \in I} \sum_{j \in J} c_{3 j} z_{i j}^{t}-\sum_{t \in T} \sum_{i \in I} \sum_{j \in J} c_{4 j} y_{i j}^{t},
\end{aligned}
$$

subject to:

$$
\sum_{i \in I} x_{i j}^{t}=P_{j}^{t} \quad \forall t \in T, j \in J
$$


Table 3. Notations used in the proposed mathematical program.

\begin{tabular}{ll}
\hline \multicolumn{1}{c}{ Notations } & \multicolumn{1}{c}{ Definition } \\
\hline Sets: & Set of planning periods \\
$\mathrm{T}$ & Set of potential sites for opening bank branches \\
$I$ & Set of types of branches (individual, entrepreneur, corporate, and commercial) \\
$J$ & Set of sites of current branches in service (a subset of set $I$ ) \\
$K$ & Set of sites of the current branches that cannot be closed in a specified period by the strategy \\
& (branches opened in the last $e$ periods)
\end{tabular}

\section{Indices :}

$\begin{array}{ll}t & \text { Planning periods (annually) } \\ i, m & \text { Potential site to open a bank branch } \\ j & \text { Type of branch (individual, entrepreneur, corporate, and commercial) }\end{array}$

\section{Parameters :}

$$
h_{i j}^{t}
$$

$d_{i m} \quad$ Distance between the potential sites of $i$ and $m$ (in meters)

$k_{i m}$

\section{Decision variables:}

$\lambda_{i m j}^{t}$
$x_{i j}^{t}$
$y_{i j}^{t}$
$z_{i j}^{t}$
by pairwise comparison.
Average transaction volume of potential site $i$, when $a$ type $j$ branch is located insite $i$, in period $t . h_{i j}^{t}$ is forecasted according to the criteria identified and their relative importance specified

Parameter depending on the distance between $i$ and $m$ (takes value between 0 and 1 )

The number of branches for type $j$ to be opened in period $t$

The number of subsequent periods in which a new opened branch cannot be closed, $(e>1)$

Threshold (in meters) to consider the penalty for opening branches near each other

Benefit coefficient (as percentage) of transaction volume $f$ or opening a type $j$ branch

Penalty coefficient (as percentage) for opening type $j$ branches near each other

Penalty coefficient (as percentage) for opening a type $j$ branch

Penalty coefficient (as percentage) for closing a type $j$ branch

Penalty of having an open type $j$ branch in both sites $i$ and $m$ at time $t$

Binary variable which is 1 if a type $j$ branch is located at site $i$ in period $t$, and 0 otherwise Binary variable which is 1 if a type $j$ branch in location $i$ is closed in period $t$, and 0 otherwise Binary variable which is 1 if a type $j$ branch in location $i$ is opened in period $t$, and 0 otherwise

$$
\begin{aligned}
\lambda_{i m j}^{t} & \geq k_{i m}\left(x_{i j}^{t}+x_{m j}^{t}-1\right) \\
& \forall t \in T, i, m \in I, i \neq m, j \in J
\end{aligned}
$$

$$
\begin{aligned}
& z_{i j}^{t+1} \geq x_{i j}^{t+1}-x_{i j}^{t} \quad \forall t \in 1, \ldots, T-1, i \in I, j \in J \\
& z_{i j}^{1} \geq x_{i j}^{1} \quad \forall i \notin K, j \in J \\
& y_{i j}^{t+1} \geq x_{i j}^{t}-x_{i j}^{t+1} \quad \forall t \in 1, \ldots, T-1, i \in I, j \in J
\end{aligned}
$$

$y_{i j}^{1} \geq\left(1-x_{i j}^{1}\right) \quad \forall i \in K, j \in J$

$$
\sum_{t=1}^{e-1} y_{i j}^{t}=0 \quad \forall i \in L, j \in J
$$

$$
\begin{gathered}
e\left(1-z_{i j}^{t}\right) \geq \sum_{k=1}^{\min \{e, T-t\}} y_{i j}^{t+k}=0 \\
\forall t \in 1, \ldots, T-1, i \in I, j \in J, \\
x_{i j}^{t}, y_{i j}^{t}, z_{i j}^{t} \in\{0,1\} \quad \forall t \in T, i \in I, j \in J, \\
\lambda_{i m j}^{t} \geq 0 \quad \forall t \in T, i, m \in I, j \in J .
\end{gathered}
$$

The objective function is used for maximizing the total profit in all the periods (the difference 
between transaction volume and the cost of opening branches near each other as well as opening and closing branches). In fact, the four parts of the objective function are the criteria determined in the previous section (see Table 2). In order to obtain comparable units of measurement for the four criteria and to allow for an inter-criteria comparison such as the aggregation proposed in the objective function, each criterion score is normalized to $0-1$ interval.

Constraints (1) show the total number of branches of each type as equal to a pre-determined number $P_{j}^{t}$. Constraints (2) indicate the penalty of opening the same type of branches near each other according to the distances $\left(d_{i m}\right)$ and threshold values $(S) . \lambda_{i m j}^{t}$ shows the penalty of opening branches of type $j$ in period $t$ in candidate sites $i$ and $m$, considering a value between 0 and 1 ( 1 if the distance between branches is $0 ; 0$ if the distance is greater than a pre-defined value $S$ ). It is clear that $\lambda_{i m j}^{t}$ will be 0 in case a branch is not opened in site $i$ or $m$ in period $t$. On the other hand, $k_{i m}$ is defined to guarantee that $\lambda_{i m j}^{t}$ obtain the right values and is formulated according to the distance between candidate sites $i$ and $m$, as shown in Figure 1. $\lambda_{i m j}^{t}$ takes the same value as $k_{i m}$ if both locations $i$ and $m$ are selected to open new branches in period $t$, and 0 otherwise.

Constraints (3) are used to ensure if a branch exists in period $t+1\left(x_{i j}^{(t+1)}=1\right)$ and does not exist in period $t\left(x_{i j}^{t}=0\right)$; then, it is opened in period $t+1\left(z_{i j}^{(t+1)}=1\right)$. Constraints (4) represent a special case of Constraint (3) for $t=0$ to give the initial configuration of the existing branches. Constraints (5) are used to ensure that the variable related to closed branches $\left(y_{i j}^{(t)}\right)$ takes proper values. It is indicated here that $y_{i j}^{t}$ will take a value beginning from the second period by ensuring that $y_{i j}^{(t+1)}=1$, if $x_{i j}^{t}=1$ and $x_{i j}^{(t+1)}=0$. Constraints (6) are a special case of Constraint (5) for $t=0$ to provide the initial configuration of non-existing branches.

In this formulation, we assume that banks avoid

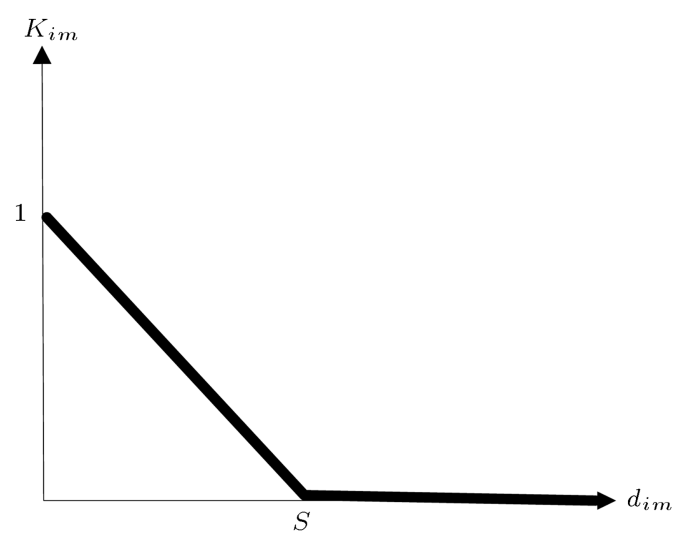

Figure 1. The relation between the distance and the threshold value. closing branches that have been open over the last $e$ periods in order to protect the bank's prestige. Therefore, Constraints (7) show that the current branches opened in recent times cannot be closed until they complete $e$ periods in service. Similarly, Constraints (8) guarantee that new opened branches provide service for at least $e$ periods. Constraints (9) and (10) indicate that decision variables are binary and penalties are nonnegative. In each period, the model provides an opportunity to open new branches and close some current ones, simultaneously. Finally, in each location, it is permitted to open at most one branch of the same type, although multiple branches with different types can be opened in the same potential site in each period.

We can prove that the proposed multi-period optimization problem is NP-hard where $L=\phi, \lambda_{i m j}^{t}=$ 0 , and $|T|=1$, meaning that (1) all the branches can be closed; (2) the distance between all the candidate sites is higher than $S$; $(3)$ the problem is defined for a single-period. In such a case, the problem becomes MCLP known as NP-hard, and an optimal solution to the proposed mathematical program is not expected to be obtained for large-sized problems [69].

\subsection{TS procedure}

Large cities provide high profit potential and increased scope for competition between banks. Therefore, banks prefer to locate their branches in metropolitan areas with lots of candidate locations. On the other hand, solving the proposed mathematical program optimally is almost impossible for large cities due to the complexities described in Section 3.2. Thereby, efficient metaheuristic methods are required to find a good solution to the proposed problem.

Justification of the TS approach is based on the studies published in recent years. For instance, it was argued that TS found better solutions than genetic algorithm and simulated annealing [70-72]. Moreover, it was demonstrated that TS produced efficient results for a multi-period mathematical model proposed for an emergency service station location problem [33]. Accordingly, we recommend a TS method to solve the multi-period mathematical model, presented in Section 3.2. TS begins with an initial solution, searching the neighbors of the current solution iteratively to improve the best solution. It forbids a definite set of moves using a tabu list and prevents the recurring solutions. If a tabu move gives a better solution than a threshold value, it is accepted as a current solution. In the literature, there are wide ranges of optimization problems using TS due to its effectiveness [73,74]. Interested readers are referred to [75] for a comprehensive tutorial on TS.

\subsubsection{Proposed TS algorithm}

Starting from an initial feasible solution, in each 


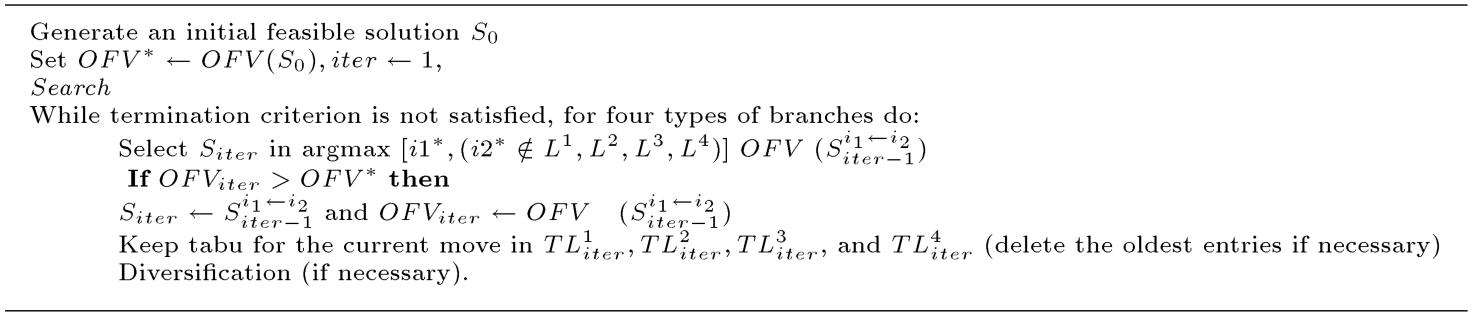

Algorithm 1. Tabu search.

iteration of TS, we investigate the candidate solution that highly promotes the solution quality (Objective Function Value - $O F V$ ) among all possible moves for the four types of branches without violating feasibility conditions. If this candidate move is not tabu and, also, improves the current best solution, we accept it. If it is tabu and the aspiration criterion is satisfied by improving the current best solution, again, we accept it for the next iteration. Otherwise, we investigate another candidate solution.

The objective function of TS approach is the same as that in the mathematical program. The general structure of the proposed TS is introduced in Algorithm 1, and the proposed TS procedure is shown in Figure 2.

\section{Notation}

- $S_{0}$ : Initial solution;

- iter: Number of iterations;

- $L_{1}, L_{2}, L_{3}$, and $L_{4}$ : Set of branches which cannot be closed due to company strategy for individual, entrepreneur, corporate, and commercial branches, respectively;

- $S_{\text {iter }}$ : The solution in iteration iter as a list of open branches for the current solution;

- $S_{i t e r}^{i 1 \leftarrow i 2}$ : Solution obtained from $S_{i t e r}$ by closing a branch in location $i_{2}$ and opening a branch of the same type in location $i_{1}$ instead;

- $O F V^{*}$ : Best-so-far $O F V$;

- $T L_{i t e r}^{1}, T L_{i t e r}^{2}, T L_{i t e r}^{3}$, and $T L_{i t e r}^{4}$ : The tabu lists for individual, entrepreneur, corporate, and commercial branches, respectively, for the current iteration.

Tabu lists have a dimension of tabu tenure $* 2$ in order to keep closed and opened branches in the same list.

In addition to the notations given above, TABU used in Figure 2 addresses the set of moves which are forbidden and does not satisfy the aspiration criterion; counter keeps track of the consecutive number of iterations of $O F V^{*}$ failure to improve for diversification.

\subsubsection{Initial solution}

In our TS method, Multi-Period LP-Relaxation Method (MPPRM) is used to generate an initial feasible solution. Similar to a plunging heuristic, in MPPRM, the initial solution is set to the solution of the LP relaxation of the proposed mathematical program for a single period. According to [5,33], MPPRM provides better solutions than different initialization approaches, such as random or greedy heuristics, for the particular problem. Because all feasibility constraints (Eqs. (1), (7), and (8)) are satisfied by opening $P_{j}^{t}$ branches and not closing the branches opened in the last three years, the result of MPPRM is feasible. In MPPRM, binary variables (i.e., $x_{i j}^{t}, y_{i j}^{t}$, and $z_{i j}^{t}$ ) are relaxed, and the LP is solved for each period separately, beginning from the first period. In this respect, the candidate points (as many as $P_{j}^{1}$ with the highest $x_{i j}^{1}$ values for each branch type) are selected to locate the branches in the first period. By fixing the solution found for the first period, the model is solved for the second period, and the algorithm continues in the same way until the last period $T$.

\subsubsection{Search}

Beginning from the first period in each iteration, the TS method investigates all potential moves for different types of branches and sets a possible solution based on the one that gives the highest rise in the $O F V$. It is clear that opening and closing the same number of multiple branches may be an alternative approach; however, this may raise the computational time considerably due to the requirement to search many neighbors. Moreover, this move does not ensure better solutions. Therefore, we prefer to open and close a single branch at each iteration.

\subsubsection{Neighborhood}

A neighborhood search is suggested that does not violate the feasibility conditions of the proposed multiperiod mathematical model in Section 3.2 by closing a branch, which has not been open in the last $e$ years, and by opening a new one. The new branch cannot be opened in a place where there is another branch of the same type, and it cannot be among the ones in service in any period, simultaneously, for each type in each period. As an example for the case of $T=4$ and $e=3$, 


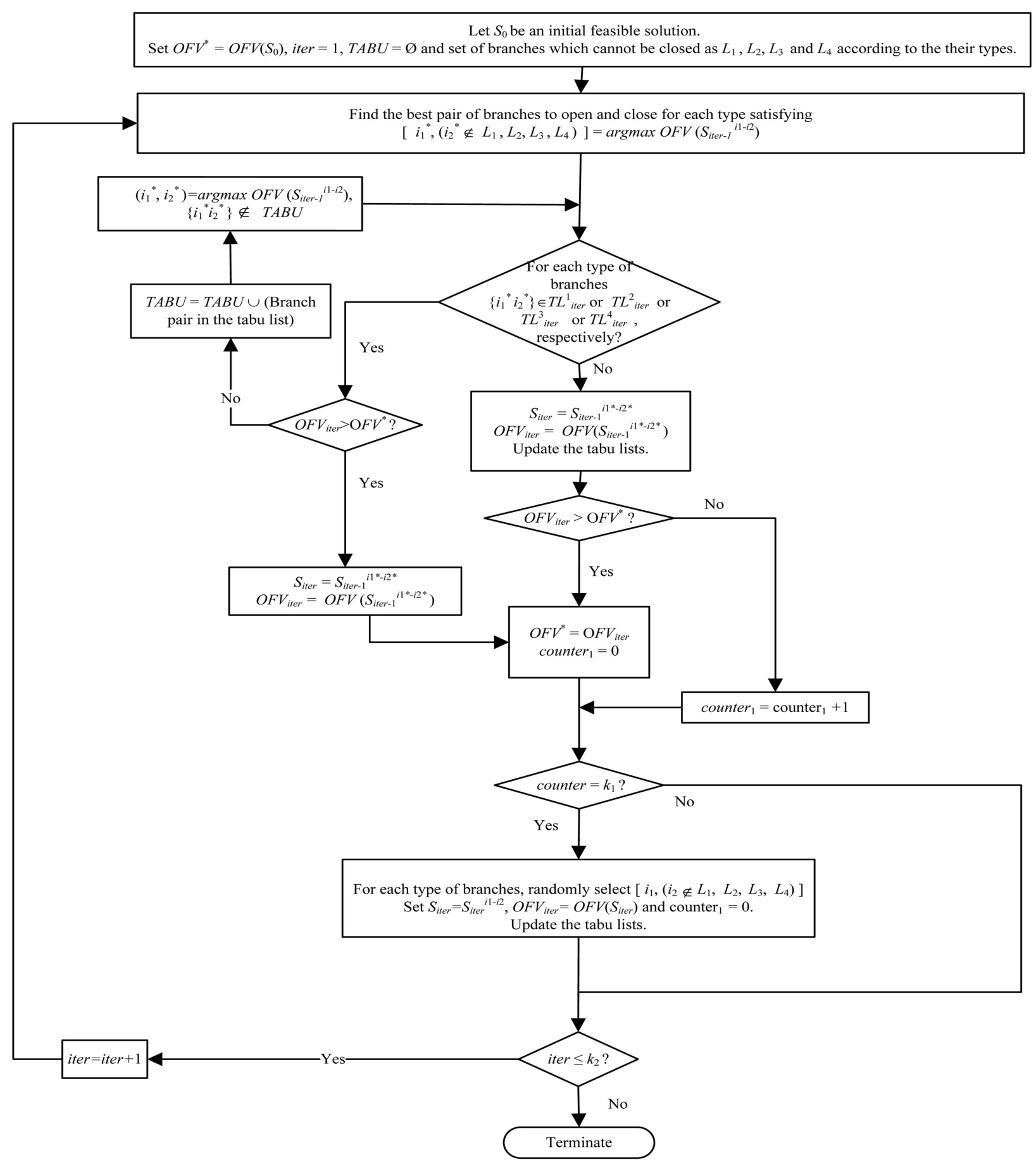

Figure 2. The proposed Tabu search algorithm.

alternative neighborhood structures are presented in Table 4.

Suppose that a current solution in an iteration is given in Table 4, the branch at point 2 remained open a year before the planning horizon, while the branches in points 5 and 8 were open more than two years ago. Therefore, since $e=3$, the branch in point 2 cannot be closed in periods $t=1$ and $t=2$. According to this information, Neighborhood Structure 2, presented in Table 4, is not feasible as it offers to close the branch at point 2 in period $t=1$. On the other hand, the same rule applies for the branches opened in the planning horizon. For instance, in the current solution, the branch in point 10 (where the current solution is 2$6-8-10$ in the second period) is opened in period $t=2$; therefore, it cannot be closed in periods $t=3$ or $t=4$ 
Table 4. Alternative neighborhood structures for multi-period TS.

\begin{tabular}{ccccccc}
\hline $\boldsymbol{t}$ & $\boldsymbol{P}_{\boldsymbol{j}}^{\boldsymbol{t}}$ & Current solution & $\begin{array}{c}\text { Neighborhood } \\
\text { Structure 1 } \\
\text { (feasible) }\end{array}$ & $\begin{array}{c}\text { Neighborhood } \\
\text { Structure 2 } \\
\text { (infeasible) }\end{array}$ & $\begin{array}{c}\text { Neighborhood } \\
\text { Structure 3 } \\
\text { (infeasible) }\end{array}$ & $\begin{array}{c}\text { Neighborhood } \\
\text { Structure 4 } \\
\text { (infeasible) }\end{array}$ \\
\hline 1 & 3 & $2-5-8$ & $2-5-8-\mathbf{1 4}$ & $2-5-8-\mathbf{1 4}$ & $2-5-8$ & $2-5-8-\mathbf{1 4}$ \\
2 & 4 & $2-6-8-10$ & $2-6-8-10-14$ & $2-6-8-10-\mathbf{1 4}$ & $2-6-8-10$ & $2-6-8-10-\mathbf{1 4}$ \\
3 & 5 & $6-7-8-10-12$ & $6-7-8-10-12-14$ & $6-7-8-10-12-14$ & $6-7-8-10-12$ & $6-7-8-10-12-14-15$ \\
4 & 6 & $6-7-9-10-12-13$ & $6-7-9-10-12-13$ & $6-7-9-10-12-13$ & $6-7-9-10-12-13-14$ & $6-7-9-10-12-13-15$ \\
\hline
\end{tabular}

(see Neighborhood Structure 3 in Table 4.). Finally, if a new branch is inserted in a new neighborhood, it should stay open in 3 periods, at least. For instance, if a branch is opened at point 14 (where the set of open branches are 2-5-8-14 in the first period with the Neighborhood Structure 4) in period $t=1$, it should not be closed in periods $t=2$ and $t=3$ (see Neighborhood Structure 4 in Table 4).

Another important constraint is associated with the number of open branches during a period for each type of branches (it should be equal to $P_{j}^{t}$ ). For instance, Neighborhood Structure 4 in Table 4 is not feasible as the number of branches in period $t=4$ is equal to 7 , which is higher than $P_{j}^{4}=6$.

In order to get a feasible neighborhood, satisfying all the mentioned constraints, we suggest closing an in-service branch which has been running for at least $e$ periods from its initial opening period and, then, opening a new branch which has not been in service in any periods. For instance, in Neighborhood Structure 1 given in Table 4 , the branch in point 8 is closed in period $t=1$, and a branch in point 14 is opened instead.

Eventually, by means of a current feasible solution and feasible neighborhoods obtained through the given method, TS maintains the feasibility in all iterations.

\subsubsection{Tabu list and aspiration criterion}

In TS algorithm, a tabu list is kept to avoid recurring solutions by preventing the same moves during a number of iterations measured by the tabu list size, thus highly affecting solution quality. Therefore, the tabu list size should be determined according to the problem size and structure. Generally, the tabu list size depending on the instance size is recommended for the problems similar to our proposed model in the literature $[76,77]$.

In the proposed TS procedure, a move is identified and, then, checked to determine whether it is included in the tabu list or not. If aspiration criterion is included, the related solution is accepted, although the move is associated with tabu. Conversely, new neighbors are searched for. The most common aspiration criterion used in the literature, which is associated with a tabu move, is applied if it provides a solution better than the current best-known solution [33].

A tabu move is defined by keeping the opened and closed branches together for each type of branches separately in different tabu lists. For each type, the exact branch pair to be closed and opened is tabu during a number of iterations.

\subsubsection{Diversification and stopping}

TS has a tendency to get stuck on a local optimum, especially after a number of iterations when it can no longer produce a more efficient result in comparison with the ones found before. Sometimes, the best-so-far solution may not change in a number of consecutive iterations. In order to deal with this problem, a diversification method is used. If the best solution cannot be improved after $k_{1}$ consecutive iterations, a new branch is opened and an existing one is closed randomly for the four types by conserving the feasibility.

Finally, a stopping criterion is set to terminate TS after $k_{2}$ iterations.

\section{Experimental study}

Before applying it to the real-life case, the proposed TS algorithm is tested, and the parameters are calibrated based on randomly generated problem instances. In the initial experiments, the value of $T$, which shows the number of years in the planning horizon, and the value of $e$, which represents the number of subsequent periods in which a newly opened branch cannot be closed, are specified as 4 and 3 (i.e., $T=4$ and $e=3$ ) as they are equal to the parameter values in the real-life case.

Here, 40 problem instances are randomly generated to test the performance of the proposed TS approach considering 5 problems, each with 50, 100, 200, $300,400,500,750$, and 1,000 candidate locations. The values of all the sub-criteria (see Table 1) for estimating transaction volume are randomly generated between 0 and 1 from the uniform distribution. Transaction volume is required to be forecasted in accordance with the relationship between the criteria. Therefore, values 
of all the criteria are normalized appropriately. To this end, the number of competitors' bank branches and the total distance to the neighboring potential branches are normalized as a cost attribute, while all the other criteria in Table 1 are evaluated as benefit attributes. By using standardized values and the importance of all criteria found by pairwise comparisons in [5], transaction volume $\left(h_{i j}^{t}\right)$ with a value between 0 and 1 is specified for each potential location. $k_{i m}$ values are calculated based on the function defined in Figure 1, after generating distances between potential locations $\left(d_{i m}\right)$ between 0 and 5.000 meters from a uniform distribution and assuming $S$ to be 1.000 meters. The number of branches to open in the first period $\left(P_{j}^{1}\right)$ is accepted as $10 \%, 4 \%, 2 \%$, and $1 \%$ among the total number of possible sites' locations for different types of branches, respectively, based on the data provided from real-life cases. Moreover, it is assumed that banks do not necessarily wish to lower the number of available branches. Thus, $P_{j}^{t}$ is assumed equal to at least the number of available branches in the previous period for each type. Furthermore, depending on the size of the problem, the sites of available branches and the ones which cannot be closed due to the strategy of a bank (sites opened in the last three years) are randomly generated. In order to avoid opening and closing a great number of branches because of randomness, a change in transaction volume beginning from the second period is specified by $+/-(20 \%)$ with respect to the transaction volume of the previous period.

By using the same processor, the TS method in Microsoft Visual $\mathrm{C}++$ is coded, and all instances with ILOG CPLEX 12.2 are solved. The results of CPLEX for 40 random instances are summarized in Table 5 .

As seen in Table 5, the optimal solution to any problem could not be found by CPLEX at the end of a maximum run time set to 10 hours. The CPLEX gap changes between $4 \%$ and $15 \%$ with an average of $10.39 \%$. As this gap is relatively low, CPLEX results $(O F V)$ as a good benchmark for our algorithm are used.

At the end of a detailed experimental study which was conducted in order to specify the parameters of TS, the best value of $k_{1}$ is set to 8 . We also observed that tabu lists of a higher size provide more efficient solutions to the problems with many potential sites. Therefore, it was decided that tabu list size should depend on the instance size. Consequently, the sizes of tabu lists for the instances having 50, 100, 300, 400, 500,750 , and 1000 are set as 5, 7, 8, 10, 13, 15, 16, and 19, respectively. Finally, algorithms with $1,000,2,500$, 5,000 , and 10,000 iterations ( $k_{2}$ parameter) are run to evaluate the efficiency of TS regarding different and long durations. Table 6 shows the results of CPLEX and TS approach for 40 random instances.

The deviation values of the proposed algorithm compared to CPLEX solutions (lower bound) are positive for all the instances in 1,000, 2,500, 5,000, and 10,000 iterations. The average deviation of TS procedure is $2.78 \%$ in $1,584.51 \mathrm{sec}, 3.94 \%$ in $4,275.79$ sec, $4.47 \%$ in $8,571.05 \mathrm{sec}$, and $4.76 \%$ in $17,542.00$ secs with $1,000,2,500,5,000$, and 10,000 iterations, respectively.

Furthermore, in order to investigate the role of $T$ and $e$ in the overall solution quality, the other combinations of $T=4,5,6$ and $e=2,3,4$ are analyzed. Appropriate initial solutions are generated using MPPRM defined in Section 3.2.2, and identical initial solutions are used for the same $T$ value. The results found at the end of $k_{2}=10,000$ iterations are given in Table 7 .

As seen in Table 7, TS finds solutions with $O F V$ characterized by $4-5 \%$ better values than those of CPLEX at the end of $k_{2}=10,000$ iterations, and solution quality does not oscillate much with different $T$ and $e$ values. Concluding the experimental analysis, it can be stated that the TS provides solutions with more efficient results than the obtained ones targeted by both computational time and $O F V$ for all the problems, regardless of the problem size, number of iterations, planning horizon, and constraint on the length of time during which a newly opened branch should be open.

\section{Case study: Locating branches of a Turkish bank in Istanbul}

The proposed TS method was applied to the multiperiod bank branch location problem of a Turkish bank in Istanbul. The data were collected by means of the Banks Association of Turkey and Turkish Statistical Institute. GIS was used to determine the possible branch sites. Istanbul has totally 763 sub-districts as candidate sites in which a new branch can be opened. The locations of available branches for each type and opening dates to apply the method were obtained. In addition, the coordinates of the sub-districts were considered as they are on the most frequent roads. The distances between candidate branches were calculated with regard to the road network via GIS; in doing so, the penalty of opening the branches with the same type nearby and ease of access for all possible sites were determined.

In order to provide input for the proposed model, the values for all the criteria are standardized and made compatible with each other. To this end, after specifying $S$ based on experts' judgment and the geographical positions of the potential sites and determining the distance $\left(d_{i m}\right)$ from road network between the bestserved potential sites, $k_{i m}$ values are calculated. $d_{i m}$ depends on the road network rather than on the direct distance between potential locations $i$ and $m$; therefore, it may not be equal to $d_{m i}$. On the other hand, since it 
Table 5. CPLEX results for $T=4$ and $e=3$.

\begin{tabular}{|c|c|c|c|c|c|c|c|c|c|c|}
\hline Instance & $\begin{array}{c}\text { No. of } \\
\text { candidate } \\
\text { locations }\end{array}$ & $\begin{array}{c}\text { No. of } \\
\text { branches } \\
\text { opened two } \\
\text { years ago } \\
\text { according } \\
\text { to their } \\
\text { types }\end{array}$ & $\begin{array}{c}\text { No. of } \\
\text { branches } \\
\text { opened } \\
\text { last year } \\
\text { according } \\
\text { to their } \\
\text { types }\end{array}$ & $\begin{array}{l}\text { No. of } \\
\text { individual } \\
\text { branches to } \\
\text { be opened } \\
\text { in each } \\
\text { period }\end{array}$ & $\begin{array}{c}\text { No. of } \\
\text { entrepreneur } \\
\text { branches to } \\
\text { be opened } \\
\text { in each } \\
\text { period }\end{array}$ & $\begin{array}{c}\text { No. of } \\
\text { corporate } \\
\text { branches to } \\
\text { be opened } \\
\text { in each } \\
\text { period }\end{array}$ & $\begin{array}{l}\text { No. of } \\
\text { commercial } \\
\text { branches to } \\
\text { be opened } \\
\text { in each } \\
\text { period }\end{array}$ & $\begin{array}{l}\text { CPLEX } \\
(O F V)\end{array}$ & $\begin{array}{l}\text { CPLEX } \\
\text { gap }(\%)\end{array}$ & $\begin{array}{c}\text { CPLEX } \\
\text { time (s) }\end{array}$ \\
\hline 1 & 50 & $0,0,0,0$ & $0,0,0,0$ & $4,5,6,6$ & $2,2,3,3$ & $1,1,1,2$ & $0,0,0,1$ & 12.875 & 4.00 & 36,000 \\
\hline 2 & 50 & $1,0,0,0$ & $0,0,0,0$ & $5,5,6,7$ & $1,1,2,3$ & $1,1,1,1$ & $0,0,0,0$ & 12.208 & 8.95 & 36,000 \\
\hline 3 & 50 & $0,0,0,0$ & $1,0,0,0$ & $5,6,7,8$ & $2,3,3,4$ & $0,1,2,2$ & $0,1,1,1$ & 15.861 & 6.33 & 36,000 \\
\hline 4 & 50 & $1,0,0,0$ & $0,0,0,0$ & $5,6,7,8$ & $2,3,3,4$ & $1,2,2,2$ & $0,0,0,1$ & 15.972 & 13.38 & 36,000 \\
\hline 5 & 50 & $0,0,0,0$ & $0,0,0,0$ & $5,6,6,7$ & $2,2,3,4$ & $0,0,1,1$ & $0,0,1,1$ & 13.704 & 9.77 & 36,000 \\
\hline 6 & 100 & $1,0,0,0$ & $0,0,0,0$ & $7,8,8,9$ & $2,2,3,4$ & $2,2,2,2$ & $1,1,1,2$ & 20.083 & 11.29 & 36,000 \\
\hline 7 & 100 & $0,0,0,0$ & $1,0,0,0$ & $8,8,9,9$ & $3,4,4,5$ & $1,2,2,3$ & $1,1,1,1$ & 21.927 & 12.39 & 36,000 \\
\hline 8 & 100 & $0,0,0,0$ & $0,0,0,0$ & $9,9,9,10$ & $4,5,6,6$ & $1,1,2,2$ & $1,1,2,2$ & 25.136 & 12.54 & 36,000 \\
\hline 9 & 100 & $0,0,0,0$ & $1,0,0,0$ & $10,11,12,13$ & $4,5,6,7$ & $1,1,1,2$ & $0,0,1,1$ & 27.108 & 8.48 & 36,000 \\
\hline 10 & 100 & $1,0,0,0$ & $0,0,0,0$ & $10,11,12,12$ & $4,4,5,6$ & $1,2,2,2$ & $1,1,1,2$ & 27.274 & 10.18 & 36,000 \\
\hline 11 & 200 & $0,1,0,0$ & $0,0,0,0$ & $13,13,13,14$ & $6,7,7,8$ & $2,2,3,3$ & $1,1,2,2$ & 35.192 & 11.62 & 36,000 \\
\hline 12 & 200 & $0,0,0,0$ & $1,1,0,0$ & $15,16,17,18$ & $7,7,8,8$ & $3,4,4,4$ & $2,2,2,3$ & 43.409 & 4.93 & 36,000 \\
\hline 13 & 200 & $1,0,0,0$ & $1,1,0,0$ & $17,18,18,19$ & $8,9,10,10$ & $4,4,5,5$ & $2,3,3,3$ & 49.732 & 10.12 & 36,000 \\
\hline 14 & 200 & $0,0,0,0$ & $1,0,0,0$ & $19,20,21,22$ & $8,8,9,9$ & $3,4,5,5$ & $2,2,3,3$ & 51.884 & 11.27 & 36,000 \\
\hline 15 & 200 & $1,0,0,0$ & $0,0,0,0$ & $20,21,22,23$ & $8,8,9,9$ & $4,5,5,6$ & $2,2,2,3$ & 52.172 & 12.52 & 36,000 \\
\hline 16 & 300 & $2,0,0,0$ & $0,1,0,0$ & $12,13,14,15$ & $5,6,7,8$ & $3,3,4,5$ & $1,2,2,2$ & 35.910 & 8.75 & 36,000 \\
\hline 17 & 300 & $0,0,0,0$ & $1,0,0,0$ & $16,18,18,19$ & $7,7,8,8$ & $4,4,4,5$ & $1,1,1,2$ & 44.835 & 5.15 & 36,000 \\
\hline 18 & 300 & $1,1,0,0$ & $0,0,0,0$ & $22,23,24,25$ & $9,10,10,11$ & $4,4,5,5$ & $1,1,1,1$ & 56.042 & 15.44 & 36,000 \\
\hline 19 & 300 & $0,0,0,0$ & $1,1,0,0$ & $26,27,28,29$ & $11,11,12,12$ & $6,7,8,9$ & $3,3,3,4$ & 71.891 & 12.63 & 36,000 \\
\hline 20 & 300 & $0,0,1,1$ & $1,1,0,0$ & $30,32,33,33$ & $12,13,14,14$ & $6,6,7,7$ & $3,3,4,4$ & 78.532 & 13.41 & 36,000 \\
\hline 21 & 400 & $1,1,0,0$ & $0,0,0,0$ & $22,24,24,26$ & $9,10,11,12$ & $5,6,7,8$ & $1,2,2,3$ & 61.309 & 5.18 & 36,000 \\
\hline 22 & 400 & $1,1,0,0$ & $1,0,0,0$ & $28,28,29,30$ & $11,11,12,13$ & $6,7,7,8$ & $1,1,1,2$ & 70.442 & 10.32 & 36,000 \\
\hline 23 & 400 & $0,0,1,0$ & $1,0,0,0$ & $32,33,34,34$ & $13,14,14,15$ & $6,7,8,8$ & $2,3,3,3$ & 82.537 & 8.79 & 36,000 \\
\hline 24 & 400 & $0,1,0,0$ & $2,0,1,0$ & $36,38,38,39$ & $15,16,17,17$ & $8,8,9,9$ & $3,4,4,4$ & 94.719 & 7.58 & 36,000 \\
\hline 25 & 400 & $1,1,1,0$ & $1,0,0,1$ & $40,41,43,45$ & $16,17,17,18$ & $8,9,9,9$ & $4,4,5,5$ & 103.508 & 7.77 & 36,000 \\
\hline 26 & 500 & $1,0,0,0$ & $1,0,1,0$ & $32,33,35,36$ & $14,15,15,16$ & $7,8,8,9$ & $1,1,2,2$ & 82.916 & 9.46 & 36,000 \\
\hline 27 & 500 & $0,1,0,0$ & $1,0,0,0$ & $38,39,40,41$ & $15,15,16,17$ & $8,9,10,10$ & $2,2,2,3$ & 96.382 & 9.95 & 36,000 \\
\hline 28 & 500 & $1,1,0,0$ & $0,0,1,0$ & $44,45,46,47$ & $17,18,18,19$ & $9,9,10,11$ & $3,3,4,4$ & 110.683 & 13.95 & 36,000 \\
\hline 29 & 500 & $0,1,1,0$ & $1,0,0,0$ & $46,48,48,49$ & $19,20,21,21$ & $10,11,12,13$ & $4,5,5,5$ & 118.472 & 14.24 & 36,000 \\
\hline 30 & 500 & $1,0,0,1$ & $0,1,1,0$ & $50,52,54,55$ & $20,21,21,22$ & $10,12,14,14$ & $5,5,6,6$ & 132.837 & 13.34 & 36,000 \\
\hline 31 & 750 & $0,0,1,0$ & $0,1,0,0$ & $56,59,60,61$ & $23,24,24,25$ & $12,13,13,13$ & $1,2,2,2$ & 139.057 & 8.34 & 36,000 \\
\hline 32 & 750 & $0,1,0,0$ & $2,0,1,0$ & $63,65,66,68$ & $25,26,27,28$ & $12,14,14,14$ & $2,3,3,3$ & 155.910 & 10.15 & 36,000 \\
\hline 33 & 750 & $1,0,1,0$ & $0,1,0,0$ & $68,69,70,71$ & $27,28,29,29$ & $14,15,16,16$ & $3,4,4,4$ & 168.282 & 12.93 & 36,000 \\
\hline 34 & 750 & $0,1,0,0$ & $1,0,1,0$ & $72,74,75,76$ & $29,30,30,32$ & $15,15,17,17$ & $5,6,6,6$ & 183.746 & 9.55 & 36,000 \\
\hline 35 & 750 & $1,0,1,0$ & $1,1,0,1$ & $75,78,79,80$ & $30,32,33,34$ & $15,16,18,18$ & $5,5,6,6$ & 190.681 & 8.52 & 36,000 \\
\hline 36 & 1,000 & $2,0,1,0$ & $2,1,0,0$ & $84,86,88,89$ & $32,33,33,35$ & $16,16,17,18$ & $6,6,7,8$ & 208.153 & 7.37 & 36,000 \\
\hline 37 & 1,000 & $1,1,0,1$ & $4,1,2,0$ & $87,88,89,90$ & $34,35,37,37$ & $17,17,18,19$ & $7,8,9,10$ & 217.952 & 14.84 & 36,000 \\
\hline 38 & 1,000 & $2,1,2,0$ & $4,2,1,1$ & $92,93,94,95$ & $36,36,38,38$ & $18,18,19,20$ & $8,8,9,9$ & 232.835 & 14.84 & 36,000 \\
\hline 39 & 1,000 & $3,2,1,1$ & $3,1,3,0$ & $96,97,98,99$ & $38,39,39,40$ & $19,19,20,20$ & $9,10,10,10$ & 237.886 & 13.77 & 36,000 \\
\hline \multirow[t]{2}{*}{40} & 1,000 & $5,1,2,1$ & $2,3,2,1$ & $100,100,100,100$ & $40,40,40,40$ & $20,20,20,20$ & $10,10,10,10$ & 243.907 & 11.75 & 36,000 \\
\hline & & & & & & & & Average & 10.39 & 36,000 \\
\hline
\end{tabular}

refers to the distance between locations $i$ and $m$, it is assumed to be unvarying during the planning horizon. Thus, $k_{i m}$ also takes the same values in each period.

Furthermore, transaction volume of the candidate locations is estimated according to the relation between the criteria. For this purpose, values of all the criteria are normalized by considering the effect, e.g., while the number of bank branches of competitors and the total distance to the neighboring candidate locations are normalized as a cost factor, the remaining criteria (total population, education level, number of financial institutions, etc.) are assessed as benefit factors. 
Table 6. Benchmark of CPLEX and TS for $T=4$ and $e=3$ (average of 40 instances).

\begin{tabular}{ccc}
\hline & $\begin{array}{c}\text { Average TS } \\
\text { time (sec) }\end{array}$ & $\begin{array}{c}\text { Average TS } \\
\text { gap (\%) }\end{array}$ \\
\hline CPLEX & 36,000 & \\
1,000 iterations & 1,585 & 2.78 \\
2,500 iterations & 4,276 & 3.94 \\
5,000 iterations & 8,571 & 4.47 \\
10,000 iterations & 17,546 & 4.76 \\
\hline
\end{tabular}

By means of standardized values and the importance of all criteria found by pair-wise comparisons (which are stable during the planning horizon), transaction volume $\left(h_{i j}^{t}\right)$ with values between 0 and 1 is specified for each potential location. Thereby, each term of the objective function takes a value between 0 and 1 .

At the time of the applied study, there are 152 individuals, 18 entrepreneurs, 12 corporates, and 3 commercial branches, respectively, owned by the Turkish Bank in Istanbul. On the other hand, 16 individual branches, 18 entrepreneur branches, 10 corporate branches, and 1 commercial branch cannot be closed in the first period because of the bank's strategy (opened in the last three years where $e=3$ ). According to experts' opinions and the structure of Istanbul's subdistricts, we set $S$ to 1.000 meters.

Additionally, the pairwise comparisons found in Section 3.1 are used as the parameters of the objective function to derive transaction volume.

Over the four-year planning horizon (i.e., $T=4$ ), the bank seeks to shift the number of its branches in Istanbul as follows: for individual branches, 161, 169, 175, and 183; for entrepreneur branches, 20, 23, 25, and 28; for corporate branches, 13, 13, 15, and 16; for commercial branches, 3, 4, 4, and 5 for four periods, respectively. We used $k_{1}=8$ and size of the tabu list $=16$ (according to the random problem with 750 potential sites) according to the best values of the TS parameters obtained in our experimental study. Similar to the experimental study with random data, MPPRM is used as the initialization method. Lastly, the solutions of the TS method with the number or iterations $k_{2}=5.000$ and 10.000 are shown in Table 8 .

It was found that the solution of CPLEX was very close to the upper bound (CPLEX gap is 0.51\%) at maximum time with 10 hours. However, the proposed TS outperformed CPLEX in both 5.000 and 10.000 iterations in a shorter amount of time. As given in Table 8 , the TS solution is $0.29 \%$ and $0.37 \%$ better than CPLEX solution in $k_{2}=5.000$ and 10.000 iterations.

According to the TS results, at the end of $k_{2}=$ 10,000 iterations, we observe that, in the first period, there are 14 individual branches to be closed and 23 branches to be opened, five entrepreneur branches to be closed and seven branches to be opened, and two corporate branches to be closed and three branches to be opened. It is seen that the number of commercial branches (3) does not change, although the location of a branch changes. The outcomes of the four-year multi-period location problem for the branches of the bank are shown in Figure 3. As explained in the mathematical model, it is allowed to open branches of different types in the same site. According to Figure 3, branches in the western part of Istanbul are

Table 7. Benchmark of CPLEX and TS for varying $T$ and $e$ values (average of 40 instances).

\begin{tabular}{|c|c|c|c|c|c|c|c|}
\hline & \multirow[b]{2}{*}{ CPLEX time } & \multicolumn{2}{|c|}{$e=2$} & \multicolumn{2}{|c|}{$e=3$} & \multicolumn{2}{|c|}{$e=4$} \\
\hline & & $\begin{array}{c}\text { TS time } \\
(\mathrm{sec})\end{array}$ & $\begin{array}{c}\text { TS gap } \\
(\%)\end{array}$ & $\begin{array}{c}\text { TS time } \\
(\mathrm{sec})\end{array}$ & $\begin{array}{c}\text { TS gap } \\
(\%)\end{array}$ & $\begin{array}{c}\text { TS time } \\
(\mathrm{sec})\end{array}$ & $\begin{array}{c}\text { TS gap } \\
(\%)\end{array}$ \\
\hline$T=4$ & 36,000 & $17,229.33$ & 4.80 & $17,542.00$ & 4.76 & $17,247.76$ & 4.69 \\
\hline$T=5$ & 36,000 & $17,246.25$ & 4.57 & $17,203.97$ & 4.43 & $17,289.52$ & 4.37 \\
\hline$T=6$ & 36,000 & $17,279.10$ & 4.60 & $17,250.81$ & 4.22 & $17,274.23$ & 4.08 \\
\hline
\end{tabular}

Table 8. Results of TS for the case study.

\begin{tabular}{|c|c|c|c|c|c|c|c|c|c|c|c|c|c|c|}
\hline$t$ & 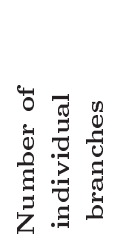 & 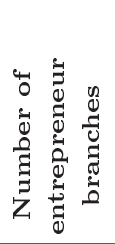 & 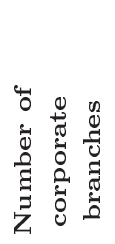 & 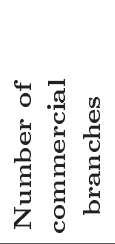 & 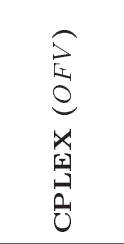 & $\begin{array}{l}\text { ब0 } \\
0 \\
0 \\
0 \\
x \\
6 \\
0 \\
0 \\
0\end{array}$ & 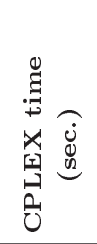 & 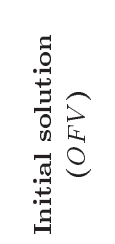 & 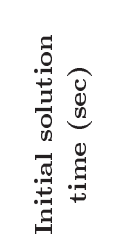 & 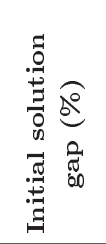 & 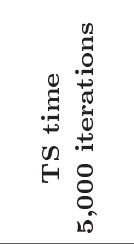 & 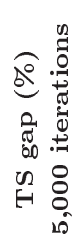 & 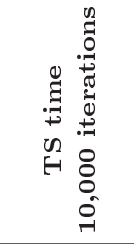 & 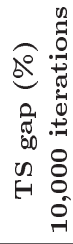 \\
\hline 1 & 161 & 20 & 13 & 3 & \multirow{4}{*}{160.814} & \multirow{4}{*}{0.51} & \multirow{4}{*}{36,000} & \multirow{4}{*}{104.782} & \multirow{4}{*}{$1,415.07$} & \multirow{4}{*}{-34.84} & \multirow{4}{*}{$17,515.38$} & \multirow{4}{*}{0.29} & \multirow{4}{*}{$34,970.53$} & \multirow{4}{*}{0.37} \\
\hline 2 & 169 & 23 & 13 & 4 & & & & & & & & & & \\
\hline 3 & 175 & 25 & 15 & 4 & & & & & & & & & & \\
\hline 4 & 183 & 28 & 16 & 5 & & & & & & & & & & \\
\hline
\end{tabular}




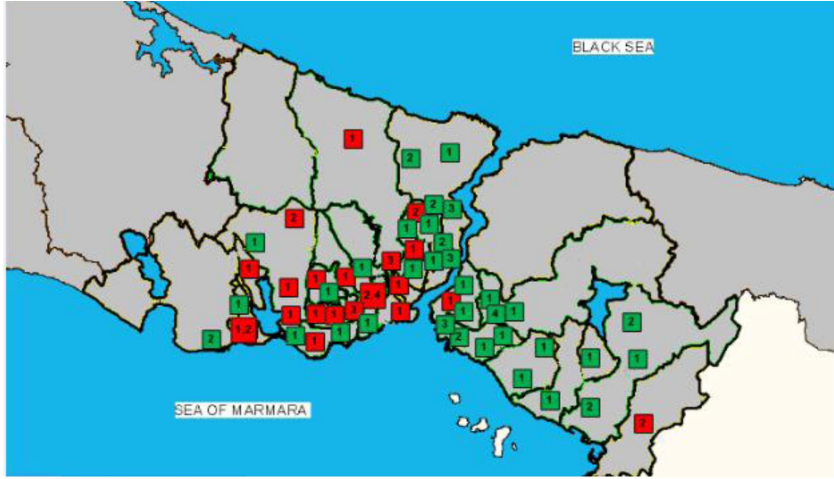

(a) Year 1 (TS Results for the 1. Period Compared to the Current Situation)

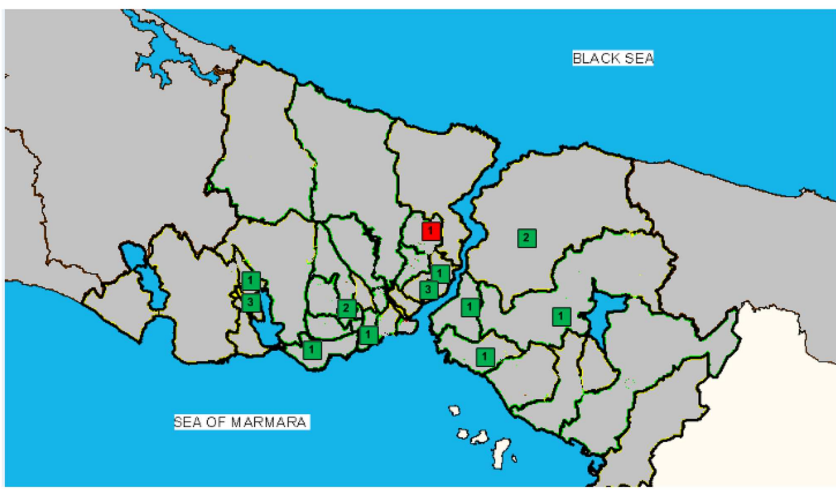

(c) Year 3 (TS Results for the 3. Period Compared to the 2. Period)

Closing an individual branch Opening an individual branch
Closing an entrepreneur branch

Opening an entrepreneur branch

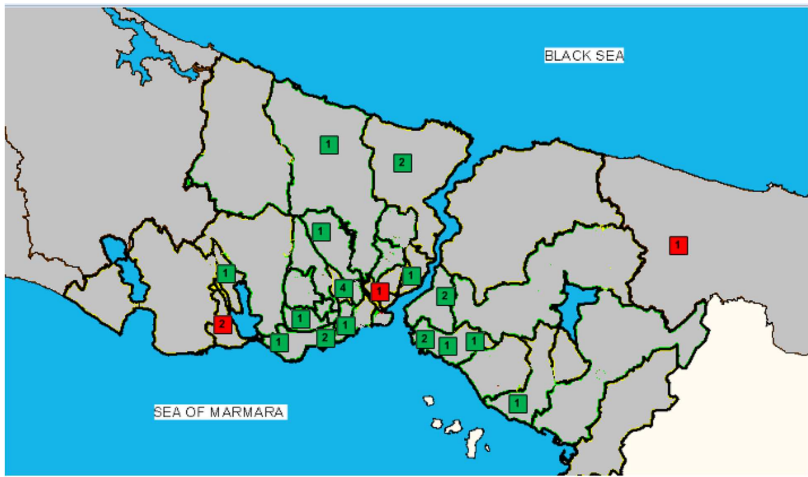

(b) Year 2 (TS Results for the 2. Period Compared to the 1. Period)

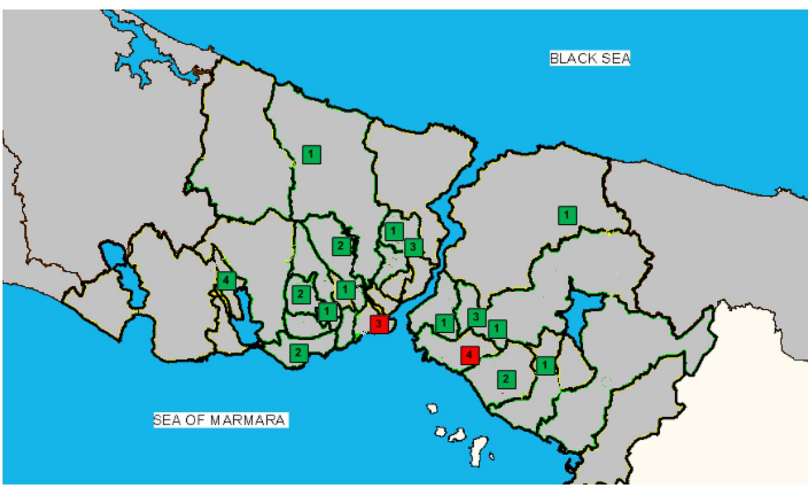

(d) Year 4 (TS Results for the 4. Period Compared to the 3. Period)

Closing a corporate branch

Opening a corporate branch

Closing a commercial branch Opening a commercial branch

Figure 3. TS solution for the 4-year branch location problem of a Turkish national bank branches in Istanbul.

mostly closed, since most of the available branches are in service in these parts. The network is expanded after closing branches located close to each other and opening new branches in the easily accessible sites. Experts working as managers in the Turkish bank also endorsed the results of the solutions.

As seen in Figure 3, the western and eastern sides are divided by the Istanbul Bosporus. In the first period, closed branches are largely situated in the western part of the Istanbul, since a significant number of the available branches are in service in this area, and about half of the new opened branches are located on the eastern side due to the lack of current branches and attracting inhabitants of Istanbul with its developing districts as shown in Figure 3(a). There are only a few closed branches in the sec, third, and fourth periods. This shows that the solution found in the first period is efficient. It is seen that potential sites with high transaction volume and no branches nearby are chosen to open new branches to enlarge service network.

We have also applied TS to the single-period problem in [5]. When the location decisions of the single-period problem and those of the multi-period problem are compared, no marginal difference is observed. However, when the whole time horizon is considered, the branch configuration is adapted to the needs of the further years through new branches opened and closed in the following years. Therefore, the multiperiod problem can be considered as more reliable for the strategic decisions given for multiple periods.

Sensitivity analysis was conducted to validate the solutions and assess the robustness via the four main criteria. The importance of the main criteria was changed by $\pm 10 \%$ and $\pm 20 \%$. According to the analyses, the solution remains the same with the changes by $+10 \%$ and $-10 \%$ and differs slightly by changes $+20 \%$ and $-20 \%$ of the four criteria at the end of $k_{2}=10.000$ iterations. Thereby, the method is found to be robust.

\section{Conclusion and further research}

This study presented a new method for multi-period bank branch location problems. A new mathematical model program was developed to find the exact places of the bank branches. This model allows one to 
open and close the branches simultaneously, meaning that it can be applied for both deciding on the right locations and evaluating the performance of current branches. Since the decision version of the optimization problem is NP-Hard and the computational time even for the small problems might be very long with an exact method, a TS method was improved. Based on experimental analyses, for all the random problems, the TS is better than CPLEX targeted by computational time and $O F V$.

The suggested approach was applied to the branch location decision of a Turkish bank in Istanbul in a four-year period. It was observed that the solutions were robust and acceptable via experts' judgment and sensitivity analysis. The proposed TS algorithm can be applied to different multi-period location problems other than bank branches thanks to its search and neighborhood structure. Moreover, it can be used for a single-period location problem if the initial solution is changed by including only one period. On the other hand, we might simply disregard certain better solutions by selecting a candidate location from a more strictly delineated set of feasible solutions. However, the lack of real data of transaction volume, deposits, credits, and related banking outputs is an important limitation of this study. Besides, the proposed methodology may not be applicable to branch location problem in urban places where there are many branches of competitors in the same place.

In the future, using the same instances, one may apply a different heuristic (e.g., Genetic Algorithm; Ant Colony Optimization) to solve the problem and benchmark with the results obtained by TS. The suggested method can be applied to another bank to analyze the effects of differences on the solutions. The proposed method may also be carried out for similar site selection problems (e.g., restaurants).

\section{References}

1. Demirguc-Kunt, A. and Maksimovic, V. "Law, finance, and firm growth", J. Financ., 53, pp. 2107-2137 (1998).

2. Levine, R. and Zervos, S. "Stock markets, banks, and economic growth", Am. Econ. Rev., 88, pp. 537-558 (1998).

3. Turkish Banks Association, Banking and Sector Information (2017). http://www.tbb.org.tr/tr/banka-vesektor-bilgileri/ba nka-bilgileri/subeler/65, accessed 15 March 2017.

4. Retail Banker International, US Branch Numbers Fall for Fourth Year Running (2014). https:// dscqm8cqg6d5o.cloudfront.net/uploads/articles/pdfs/ mnetisgnefhmblsrdclkablzye_rbioct13issue694 usbranches.pdf, accessed 24 April 2017.

5. Basar, A., Kabak, O., Topcu, Y.I., and Bozkaya, B.
"Location analysis in banking: A new methodology and application for a Turkish bank", In: Eiselt, H.A. and Vladimir, M. (Eds), Applications of Location Analysis, Springer, pp. 25-54 (2014).

6. Rajagopalan, H.K., Saydam, C., and Xiao, J. "A multiperiod set covering location model for dynamic redeployment of ambulances", Comput. Oper. Res., 35, pp. $814-826$ (2008).

7. Manandhar, R. and Tang, J.C.S. "The evaluation of bank branch performance using data envelopment analysis: a framework", Journal of High Technology Management Research, 13, pp. 1-17 (2002).

8. Cook, W.D., Seiford, L.M., and Zhu, J. "Models for performance benchmarking: Measuring the effect of ebusiness activities on banking performance", Omega, 32, pp. 313-322 (2004).

9. Camanho, A.S. and Dyson, R.G. "Cost efficiency measurement with price uncertainty: A DEA application to bank branch assessments", Eur. J. Oper. Res, 161, pp. 432-446 (2005).

10. Portela, M.C.A.S. and Thanassoulis, E. "Comparative efficiency analysis of Portuguese bank branches", Eur. J. Oper. Res., 177, pp.1275-1288 (2007).

11. Paradi, J.C. and Zhu, H. "A survey on bank branch efficiency and performance research with data envelopment analysis", Omega, 41(1), pp. 61-79 (2013).

12. Paradi, J.C., Min, E., and Yang, X. "Evaluating Canadian bank branch operational efficiency from staff allocation: A DEA approach", Management and Organizational Studies, 2(1), pp. 52-65 (2015).

13. LaPlante, A.E. and Paradi, J.C. "Evaluation of bank branch growth potential using data envelopment analysis", Omega, 52, pp. 33-41 (2015).

14. Basar, A., Catay, B., and Unluyurt, T. "A taxonomy for emergency service station location problem", $O p$ tim. Lett., 6(6), pp. 1147-1160 (2012).

15. Arabani, A.B. and Farahani, R.Z. "Facility location dynamics: An overview of classifications and applications", Comput. Ind. Eng., 62, pp. 408-420 (2012).

16. Miller, T.C., Friesz, T.L., Tobin, R.L., and Kwon, C. "Reaction function based dynamic location modelling in Stackelberg-Nash-Cournot competition", Netw. Spat. Econ., 7(1), pp. 77-97 (2007).

17. Hale, T.S. and Moberg, C.R. "Location science research: A review", Ann. Oper. Res., 123, pp. 21-35 (2003).

18. Klose, A. and Drexl, A. "Facility location models for distribution system design", Eur. J. Oper. Res., 162(1), pp. 4-29 (2005).

19. Melo, M.T., Nickel, S., and Saldanha-da-Gama, F. "Facility location and supply chain management-A review", Eur. J. Oper. Res., 196(2), pp. 401-412 (2009).

20. Wesolowky, G.O. and Truscott, W.G. "The multiperiod location-allocation problem with relocation of facilities", Manage. Sci., 22, pp. 57-65 (1975). 
21. Schilling, D.A. "Dynamic location modeling for public sector facilities: A multi criteria approach", Decision Sci., 11, pp. 714-724 (1980).

22. Gunawardane, G. "Dynamic versions of set covering type public facility location problems", Eur. J. Oper. Res., 10(2), pp. 190-195 (1982).

23. Galvao, R.D. and Gonzalez, S.E. "A Lagrangean heuristic for the $p_{k}$-median dynamic location problem", Eur. J. Oper. Res., 58, pp. 250-262 (1992).

24. Drezner, Z. "Dynamic facility location: The progressive p-median problem", Location Science, 3, pp. 1-7 (1995).

25. Chardaire, P., Sutter, A., and Costa, M.C. "Solving the dynamic facility location problem", Networks, 28, pp. 117-124 (1996).

26. Hormozi, A.M. and Khumawala, B.M. "An improved algorithm for solving a multi-period facility location problem", IIE Trans., 28(2), pp. 105-114 (1996).

27. Current, J., Ratick, S., and ReVelle, C. "Dynamic facility location when the total number of facilities is uncertain: A decision analysis approach", Eur. J. Oper. Res., 110, pp. 597-609 (1997).

28. Antunes, A. and Peeters, D. "A dynamic optimization model for school network planning", Socio. Econ. Plan. Sci., 34(2), pp. 101-120 (2000).

29. Antunes, A. and Peeters, D. "On solving complex multi-period location models using simulated annealing", Eur. J. Oper. Res., 130(1), pp. 190-201 (2001).

30. Canel, C., Khumawala, B.M., Law, J., and Loh, A. "An algorithm for the capacitated, multi-commodity multi-period facility location problem", Comput. Oper. Res., 28(5), pp. 411-427 (2001).

31. Dias, J., Captivo, M.E., and Clímaco, J. "Efficient primal-dual heuristic for a dynamic location Problem", Comput. Oper. Res., 34, pp. 1800-1823 (2007).

32. Albareda-Sambola, M., Fernandez, E., Hinojosa, Y., and Puerto, J. "The multi-period incremental service facility location problem", Comput. Oper. Res., 36(5), pp. 1356-1375 (2009).

33. Basar, A., Catay, B., and Unluyurt, T. "A multi-period double coverage approach for locating the emergency medical service stations in Istanbul", J. Oper. Res. Soc., 62(4), pp. 627-637 (2011).

34. Torres-Soto, J.E. and Uster, H. "Dynamic-demand capacitated facility location problems with and without relocation", Int. J. Prod. Res., 49(13), pp. 3979-4005 (2011).

35. Sha, Y. and Huang, J. "The multi-period locationallocation problem of engineering emergency blood supply systems", Systems Engineering Procedia, 5, pp. 21-28 (2012).

36. Ghaderi, A. and Jabalameli, M.S. "Modeling the budget-constrained dynamic uncapacitated facility location-network design problem and solving it via two efficient heuristics: A case study of health care", Math. Comput. Model., 57(3), pp. 382-400 (2013).
37. Zarandi, M.H.F., Davari, S., and Sisakht, S.A.H. "The large-scale dynamic maximal covering location problem", Math. Comput. Model., 57(3), pp. 710-719 (2013).

38. Miskovic, S., Stanimirovic, Z., and Grujicic, I. "An efficient variable neighborhood search for solving a robust dynamic facility location problem in emergency service network", Electronic Notes in Discrete Mathematics, 47, pp. 261-268 (2015).

39. Megiddo, N. "Dynamic location problems", Ann. Oper. Res., 6(10), pp. 311-319 (1986).

40. Zanjirani Farahani, R., Abedian, M., and Sharahi, S. "Dynamic facility location problem", In: Facility Location: Concepts, Models, Algorithm and Case Studies, Springer (2009).

41. Da Gama, F.S. and Captivo, M.E. "A heuristic approach for the discrete dynamic location problem", Location Science, 6, pp. 211-223 (1998).

42. Clawson, C.J. "Fitting branch locations, performance standards, and marketing strategies to local conditions", J. Marketing, 38, pp. 8-14 (1974).

43. Boufounou, P.V. "Evaluating bank branch location and performance: A case study", Eur. J. Oper. Res., 87, pp. 389-402 (1995).

44. Ravallion, M. and Wodon, Q. "Banking on the poor? Branch location and nonfarm rural development in Bangladesh", Rev. Dev. Econ., 4, pp. 121-139 (2000).

45. Basar, A., Kabak, O., and Topcu, Y.I. "A new mathematical programming formulation for locating bank branches in Turkey", Proc. of XX EURO Working Group on Locational Analysis, (EWGLA), Ankara, Turkey: pp. 37-38 (2013).

46. Aggelopoulos, E. and Georgopoulos, A. "Bank branch efficiency under environmental change: a bootstrap DEA on monthly profit and loss accounting statements of Greek retail branches", Eur. J. Oper. Res., 261(3), pp. 1170-1188 (2017).

47. Cvetkoska, V. and Savić, G. "Efficiency of bank branches: empirical evidence from a two-phase research approach", Economic Research-Ekonomska Istraživanja, 30(1), pp. 318-333 (2017).

48. Quaranta, A.G., Raffoni, A., and Visani, F. "A multidimensional approach to measuring bank branch efficiency", Eur. J. Oper. Res., 266(2), pp. 746-760 (2018).

49. Basar, A., Kabak, O., and Topcu, Y.I. "A decision support methodology for locating bank branches: A case study in Turkey", Int. J. Inf. Tech. Decis., 16(1), pp. 59-86 (2017).

50. Min, H. "A model based decision support system for locating banks", Inform. Manage., 17, pp. 207-215 (1989).

51. Cinar, N. "A decision support model for bank branch location selection", World Academy of Science, Engineering \& Technology, 60, pp. 126-131 (2009). 
52. Rahgan, S.H. and Mirzazadeh, A. "A new method in the location problem using fuzzy evidential reasoning", Engineering and Technology, 4(22), pp. 4636-4645 (2012).

53. Morrison, P.S. and O'Brien, R. "Bank branch closures in New Zealand: The application of a spatial interaction model", Appl. Geog., 21, pp. 301-330 (2001).

54. Gorener, A., Dincer, H., and Hacioglu, U. "Application of multi-objective optimization on the basis of ratio analysis (MOORA) method for bank branch location selection", International Journal of Finance \& Banking Studies, 2(2), pp. 41-52 (2016).

55. Min, H., and Melachrinoudis, E. "The threehierarchical location-allocation of banking facilities with risk and uncertainty", Int. T. Oper. Res., 8, pp. 381-401 (2001).

56. Miliotis, P., Dimopoulou, M., and Giannikos, I. "A hierarchical location model for locating bank branches in a competitive environment", Int. T. Oper. Res., 9, pp. 549-565 (2002).

57. Wang, Q., Batta, R., Bhadury, J., and Rump, C.M. "Budget constrained location problem with opening and closing of facilities", Comput. Oper. Res., 30, pp. 2047-2069 (2003).

58. Monteiro, M. and Fontes, D. "Locating and sizing bank-branches by opening, closing or maintaining facilities", Operat. Res. Proceed., pp. 303-308 (2005).

59. Zhang, L. and Rushton, G. "Optimizing the size and locations of facilities in competitive multi-site service systems", Comput. Oper. Res., 35, pp. 327-338 (2008).

60. Alexandris, G. and Giannikos, I. "A new model for maximal coverage exploiting GIS capabilities", Eur. J. Oper. Res., 202, pp. 328-338 (2010).

61. Xia, L., Yin, W., Dong, J., Wu, T., Xie, M., and Zhao, Y. "Hybrid nested partitions algorithm for banking facility location problems", IEEE T. Autom. Sci. Eng., 7 (3), pp. 654-658 (2010).

62. Jablonsky, J., Fiala, P., Smirlis, Y., and Despotis, D.K. "DEA with interval data: An illustration using the evaluation of branches of a Czech bank", Cent. Eur. J. Oper. Res., 12, pp. 323-337 (2004).

63. Badri, M.A. "A combined AHP-GP model for quality control systems", Int. J. Prod. Econ., 72, pp. 27-40 (2001).

64. Saaty, T.L., The Analytic Hierarchy Process, New York, McGraw-Hill, Inc. (1980).

65. Ahsan, M.K. and Bartlema, J. "Monitoring healthcare performance by analytic hierarchy process: A developing-country perspective", Int. T. Oper. R., 11, pp. $465-478$ (2004).
66. Tzeng, G.H., Teng, M.H., Chen, J.J., and Opricovic, S. "Multi criteria selection for a restaurant location in Taipei", Int. J. Hosp. Manag., 21(2), pp. 171-187 (2002).

67. Wu, C.R., Lin, C.T., and Chen, H.C. "Optimal selection of location for Taiwanese hospitals to ensure a competitive advantage by using the analytic hierarchy process and sensitivity analysis", Build. Environ., 42(3), pp. 1431-1444 (2007).

68. Fernandez, I. and Ruiz, M.C. "Descriptive model and evaluation system to locate sustainable industrial areas", J. Clean. Prod., 17(1), pp. 87-100 (2009).

69. Marianov, V., ReVelle, C.S., Facility Location, Berlin, Springer (1995).

70. Silva, G.C., Bahiense, L., Ochi, L.S., and Netto, P.O.B. "The dynamic space allocation problem: Applying hybrid GRASP and tabu search metaheuristics", Comput. Oper. Res., 39(3), pp. 671-677 (2012).

71. Naama, B., Bouzeboudja, H., and Allali, A. "Application of tabu search and genetic algorithm in minimize losses in power system. Using the B-coefficient method", Energy. Proced,, 36, pp. 687-693 (2013).

72. Rosłon, J. and Zawistowski, J. "Construction projects' indicators improvement using selected metaheuristic algorithms", Procedia Engineer., 153, pp. 595-598 (2016).

73. Hamta, N., Fatemi Ghomi, S.M.T., Tavakkoli Moghaddam, R., and Jolai, F. "A hybrid meta-heuristic for balancing and scheduling assembly lines with sequenceindependent setup times by considering deterioration tasks and learning effect", Scientia Iranica, 21(3), pp. 963-979 (2014).

74. Imanipour, N. and Zegordi S.H.A.D. "A heuristic approach based on tabu search for early/tardy flexible job shop problems", Scientia Iranica, 13(1), pp. 1-13 (2006).

75. Glover, F., Taillard, E., and de Werra, D. "A user's guide to Tabu search", Ann. Oper. Res.-Special issue on Tabu search, 41(1-4), pp. 3-28 (1993).

76. Zhang, G., Habenicht, W. and Spie $\beta$, W.E.L. "Improving the structure of deep frozen and chilled food chain with tabu search procedure", J. Food Eng., 60(1), pp. 67-79 (2003).

77. Grabowski, J. and Wodecki, M. "A very fast tabu search algorithm for the permutation flow shop problem with makespan criterion", Comput. Oper. Res., 31, pp. 1891-1909 (2004).

\section{Biographies}

Ayfer Basar is a Service Manager in one of the biggest national bank's IT company in Turkey. She received her PhD degree from Istanbul Technical University (ITU) and MSc degree from Sabanci University, Istanbul in Industrial Engineering. She is a part-time Instructor in Ozyegin University, Istanbul. Her research interests include applied optimization, location 
planning, and heuristic approaches. She has published articles in indexed journals such as Journal of the Operational Research Society and Optimization Letters.

Özgur Kabak is an Associate Professor of Operations Research at ITU, Istanbul. He received his MSc and $\mathrm{PhD}$ in Industrial Engineering from ITU in 2005 and 2008 , respectively. He continued his studies in SCKChen, Belgian as a post-doc researcher in 2009. His main research interest fields of study include optimization and mathematical modeling, fuzzy decision making, and supply chain management. He has published more than 20 papers in indexed journals.

Yusuf Ilker Topcu is a Professor of Decision Sci- ences at Industrial Engineering Department of Istanbul Technical University (ITU). He holds a BSc in Industrial Engineering (1993) and MSc in Engineering Management (1995), both from ITU. He completed his PhD studies (2000) at ITU and visited Leeds University Business School during these studies (19981999). His main research interests include multiple criteria decision making, decision analysis, operations research/management science. He has published papers in several journals such as Journal of the Operational Research Society, European Journal of Operational Research, Journal of Global Optimization, Applied Mathematical Modeling, International Journal of Production Economics, and Expert Systems with Applications. 